\title{
RESULTADOS DE LA EXPERIENCIA EN LA ASIGNATURA TRABAJO FIN DE GRADO EN EL TÍTULO DE RELACIONES LABORALES Y RECURSOS HUMANOS
}

\author{
Domingo A. Manzanares Martínez \\ María Teresa Díaz Delfa \\ Facultad de Ciencias del Trabajo, Universidad de Murcia
}

DOI: $10.1387 /$ lan-harremanak. 15437

\section{ABSTRACT}

La implantación del título de Grado en Relaciones Laborales y Recursos Humanos en la Universidad de Murcia se hizo en el curso académico 2009-10. En ese mismo año ofertamos un curso de adaptación al Grado a los diplomados que titularon con el plan de estudios anterior. Esta decisión supuso que tuviésemos que organizar, planificar y gestionar la asignatura de Trabajo Fin de Grado (TFG) al tiempo que implantábamos los nuevos estudios. Así, en los últimos cinco cursos académicos, hemos acumulado una valiosa experiencia sobre la materia referida.

El TFG es una asignatura más del plan de estudios, pero con características especiales, tales como que no tiene docencia, está tutorizada por un docente a lo largo de un número determinado de sesiones, se defiende una vez cursadas y superadas todas las asignaturas que conforman el plan de estudios, etc. Nuestra comunicación presenta, para su discusión, la experiencia llevada a cabo en la Facultad de Ciencias del Trabajo de la Universidad de Murcia sobre el TFG, desde el punto de vista de la organización, gestión y evaluación de la asignatura y los resultados académicos obtenidos por los alumnos. 
Palabras clave: Trabajo Fin de Grado, rúbrica, gestión del TFG, organización docente del TFG, evaluación y resultados del TFG.

The implementation of the Degree in Labor Relations and Human Resources at the University of Murcia was in the academic year 2009-10. In the same year we offer an adaptation to the degree to graduates who titled the previous curriculum. This decision meant that we had to organize, plan and manage the subject of Final Project (TFG) while we set up new studies. Thus, in the last five academic years, we have accumulated valuable experience on the said matter. The TFG is a subject of the curriculum, but with special features, such as having no teaching, it is supervised by a teacher over a number of sessions and defends once taken and passed all the subjects included in the curriculum, etc. Our communication presents for discussion, the experiment carried out at the Faculty of Labour Sciences at the University of Murcia on the TFG, from the point of view of organization, management and evaluation of the course and the academic results obtained by students.

Key Words: Final Project, rubric, management TFG, TFG teaching organization, evaluation and results of the TFG. 


\section{Introducción}

El curso 2009/10 fue el primer año del proceso de implantación de las titulaciones de Grado en la Universidad de Murcia (UMU) y, por tanto, fue el curso académico 2012-13 cuando se presentó la primera promoción de todos aquellos títulos de duración de cuatro años. Conforme se fueron implantando los nuevos títulos, se procedió también a poner en marcha un proceso de extinción paulatino, curso a curso, de las diplomaturas y de las licenciaturas. Además, se adoptó la decisión de ofrecer la posibilidad de obtener el título de graduado/a a los ya diplomados sin tener que esperar los cuatro años necesarios para la implantación completa del título correspondiente. Para ello nuestra universidad definió el procedimiento adecuado y en el Consejo de Gobierno de 29 de julio de 2009, se aprobó la Norma sobre itinerarios para obtener el grado de los estudiantes de la Universidad de Murcia que culminen las actuales titulaciones, que preveía y diseñaba un itinerario de complementos de formación para el reconocimiento del título de Grado a todos aquellos alumnos que estuviesen en posesión del título de diplomado correspondiente. En el caso de nuestro centro el de Diplomado en relaciones laborales.

Se trataba de un proyecto piloto que sólo permitía la realización del itinerario formativo a los alumnos que terminaban sus estudios en el curso anterior. Es decir, los alumnos que pudieron matricularse en el itinerario de complementos de formación al Grado en relaciones laborales y recursos humanos del curso 2009/10, fueron los que habían terminado en el ańo 2008/09. Este curso se ofertó hasta el año 2011/12, dado que al siguiente culminaba la implantación completa del título oficial de graduado/a. El itinerario de adaptación al grado tenía un total de 42 créditos ECTS, incluyendo la realización, exposición y defensa del Trabajo Fin de Grado (TFG). En realidad, los 42 créditos de este curso de formación se corresponden con la tabla de adaptación prevista en el diseño del plan de estudios del Grado verificado para nuestra Facultad.

El Trabajo Fin de Grado es un trabajo personal y autónomo del estudiante, cuya realización tiene por objeto dar cuenta de forma integrada de los contenidos y competencias que se han adquirido con las asignaturas y/o materias que conforman el plan de estudios y que se desarrolla siempre bajo la supervisión 
de un tutor o tutora que orienta al estudiante en su elaboración. Fue el curso 2009/10 el primero en el que se presentaron y defendieron Trabajos Fin de Grado en la UMU. Para la organización del proceso hubo que dotarse de la normativa pertinente. Así, la Universidad de Murcia aprobó, el 7 de mayo de 2010, el "Reglamento por el que se regulan los Trabajos de Fin de Grado y de Fin de Máster en la Universidad de Murcia» y al amparo de este documento cada Facultad desarrolló su propia normativa. La relativa al TFG de la Facultad de Ciencias del Trabajo fue aprobada el 28 de octubre de 2010.

Durante los cursos académicos de 2009/10 a 2011/12 se han presentado y defendido TFG en varios títulos de Grado de la UMU, entre los que se encuentra el que se imparte en nuestro centro. Gracias a estas experiencias «piloto» se ha recabado información sobre las necesidades y las dificultades que hay tanto en la gestión como en la tutorización de los TFG. También ha servido a los docentes para familiarizarse con las características generales de este tipo de trabajos y para realizar las oportunas actividades formativas - presenciales y no presenciales-, ofertadas desde el centro, que tenían como finalidad la adquisición de las estrategias y competencias necesarias para llevar a cabo su nueva tarea como tutor. De esta manera se mejoraba la elaboración, desarrollo, presentación y defensa del TFG que realizarían los estudiantes.

El curso 2012/13 fue el primero en el que se presentaron y defendieron Trabajos Fin de Grado elaborados por el alumnado que había cursado los cuatro años del grado; es decir, se trataba de la primera promoción de graduados en el sentido literal. De tal modo que la experiencia acumulada durante esos ańos por los docentes y los gestores sobre la asignatura TFG, permitió que se adoptasen nuevas medidas, tanto a nivel de universidad como de los centros, para la mejora de la gestión de esta materia.

Los objetivos de esta comunicación son, básicamente dos. El primero es analizar la evolución de los trabajos presentados y los resultados académicos obtenidos hasta este momento en el período 2009-14; el segundo, presentar las acciones normativas y formativas acometidas por la UMU y por la Facultad de Ciencias del Trabajo sobre esta asignatura especial denominada Trabajo Fin de Grado.

\section{Trabajos Fin de Grado defendidos en el período 2009-14}

El TFG en nuestro Grado en Relaciones laborales y recursos humanos es una asignatura obligatoria, con una carga lectiva de 6 créditos ECTS, equivalente a 150 horas de trabajo, planificada en el segundo cuatrimestre de cuarto curso del plan de estudios. El trabajo, una vez elaborado por el estudiante, debe presentarlo y defenderlo de forma individual y pública ante un tribunal. 
El gráfico 1 recoge la evolución del número de trabajos que se defendieron en los cinco cursos académicos transcurridos en el período de referencia, 2009-14.

Gráfico 1

Trabajos Fin de Grado defendidos, 2009-14

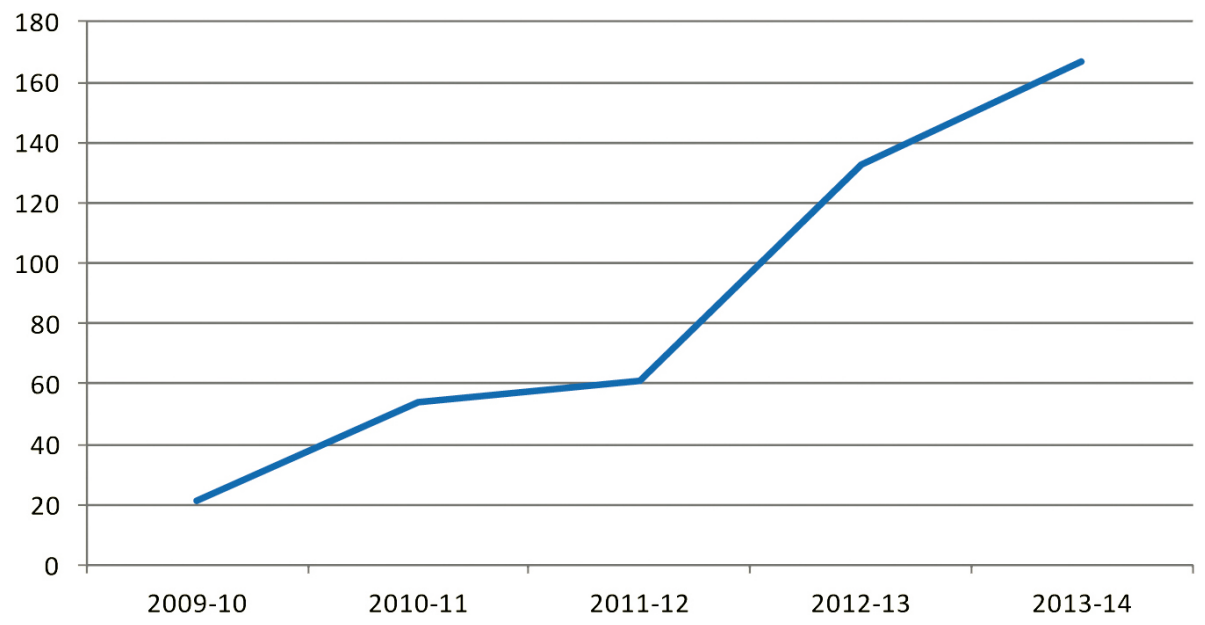

Fuente: Elaboración propia. Datos Secretaría de la Facultad de Ciencias del Trabajo.

Los primeros estudiantes que presentaron y defendieron Trabajos Fin de Grado en la Facultad de Ciencias del Trabajo fueron aquellos que habían obtenido el título de Diplomado en relaciones laborales en el curso académico 2008/09 y habían cursado el itinerario de adaptación al Grado en relaciones laborales y recursos humanos durante 2009/10. Se matricularon 31 alumnos en el TFG y se ofertaron 35 líneas de trabajos (al menos un 15\% más del número de estudiantes matriculados en primera matrícula en el TFG, como prevé nuestra normativa); de ellas, 19 eran líneas económico sociales y 16 líneas jurídico-laborales.

En el curso 2010/11 se matricularon 76 alumnos y se ofertaron 84 líneas de TFG, de las cuales 32 se ocupaban de temas jurídicos. Los alumnos eligieron 30 del ámbito jurídico (el 93,8\% de ellas) y 46 líneas socioeconómicas (el 88,5\% de esta oferta). Entre las convocatorias de junio y septiembre de 2010/11 se presentaron y defendieron $54 \mathrm{TFG}, 20(38,5 \%)$ sobre temas jurídicos y 32 $(61,5 \%)$ vinculados con áreas de conocimiento de las ciencias sociales, como organización de empresas, psicología, sociología, etc.

En el curso 2011/12 fueron 98 estudiantes los nuevos matriculados en los complementos formativos de adaptación a nuestro grado que, sumados a los interesados del año anterior, situó la matrícula total en la asignatura de TFG en 
116. De éstos, únicamente el 52,6\% presentó y defendió su trabajo. Fue un curso académico peculiar ya que la tasa de rendimiento bajó bastante respecto de los dos años anteriores, debido a que sólo defendieron su trabajo final aproximadamente la mitad de los matriculados.

El curso académico 2012/13 es el de la primera promoción propiamente dicha de graduados entre los matriculados en el TFG, es decir, los alumnos que por primera vez cursaron los cuatro años del grado. En este año académico desaparece el curso denominado itinerario de adaptación al grado en relaciones laborales y recursos humanos y, al amparo de la Norma de acceso al grado desde las Diplomaturas, Ingenierias Técnicas, Licenciaturas e Ingenierías correspondientes a la anterior ordenación (Consejo de Gobierno de 18 de marzo de 2011), se pone en marcha el Curso de Especialista en Complementos de Formación en el Grado en Relaciones Laborales y Recursos Humanos que permite a los titulados en Graduado social diplomados o Diplomados en relaciones laborales el acceso la obtención del Grado.

Una vez finalizado y aprobadas la totalidad de las asignaturas del curso de especialista por parte de los estudiantes, la comisión académica de la Facultad de Ciencias del Trabajo, tras la solicitud oportuna, les reconoce las asignaturas correspondientes para su adaptación al grado, quedándoles a éstos únicamente que realizar el Trabajo Fin de Grado para la obtención del título de Graduado/a. Con ese fin, pues, formalizan su matrícula oficial en los estudios de Grado. Este nuevo escenario hace que en este curso existan tres tipos de alumnos entre los matriculados en el TFG, dependiendo de la titulación de acceso.

Tabla 1

Procedencia de los alumnos matriculados en el TFG, curso 2012-14

\begin{tabular}{l|cc|cc}
\hline \multirow{2}{*}{\multicolumn{1}{c|}{ Procedencia }} & \multicolumn{2}{|c|}{$2012 / 13$} & \multicolumn{2}{c}{$2013 / 14$} \\
\cline { 2 - 5 } & \multicolumn{2}{|c|}{$\begin{array}{c}\text { N. o de } \\
\text { alumnos }\end{array}$} & Porcentaje & \multicolumn{2}{c}{$\begin{array}{c}\text { N.o de } \\
\text { alumnos }\end{array}$} & Porcentaje \\
\hline Grado & 80 & 43,2 & 168 & 70,9 \\
Itinerario de adaptación al grado & 41 & 22,2 & 11 & 4,6 \\
Curso de Especialista & 64 & 34,6 & 58 & 24,5 \\
\hline TOTAL & 185 & 100,0 & 237 & 100,0 \\
\hline
\end{tabular}

Fuente: Elaboración propia. Datos Secretaría de la Facultad de Ciencias del Trabajo.

Del total de matriculados en este curso académico, 133 defendieron su TFG, de los que 23 procedían del itinerario de adaptación al Grado, 47 del 
curso de especialista y 63 eran propiamente los integrantes de la primera promoción de Grado.

En el curso pasado 2013-14, segunda promoción, se matricularon 237 estudiantes en la asignatura trabajo fin de grado: de ellos, finalmente, lograron defender su trabajo 167. Como se observa la matrícula se incrementa bastante en este curso. Este hecho repercute claramente en el proceso de gestión de esta asignatura, en cuestiones que van desde la petición de líneas a las áreas de conocimiento, asignación de las mismas a los alumnos, en número de tribunales, en profesores que participan en ellos, etc.

En nuestro plan de estudios participan dieciséis áreas de conocimiento, con diferente peso específico, pertenecientes a la rama de conocimiento de ciencias sociales y jurídicas. Por su especialidad, esas áreas las podemos organizar en dos grandes ámbitos, uno el jurídico y otro el socioeconómico. Analizando la distribución de las temáticas de los trabajos defendidos en estos años entre los dos grandes ámbitos de conocimiento señalados, se puede afirmar que la tendencia es a que se mantenga una distribución del $40 / 60$ por ciento, siendo el primer dato el correspondiente a las áreas jurídicas y el segundo a las socioeconómicas. El gráfico 2 recoge la distribución explicita de cada curso académico en este periodo.

\section{Gráfico 2}

TFG defendidos por ámbito de conocimiento, 2009-14

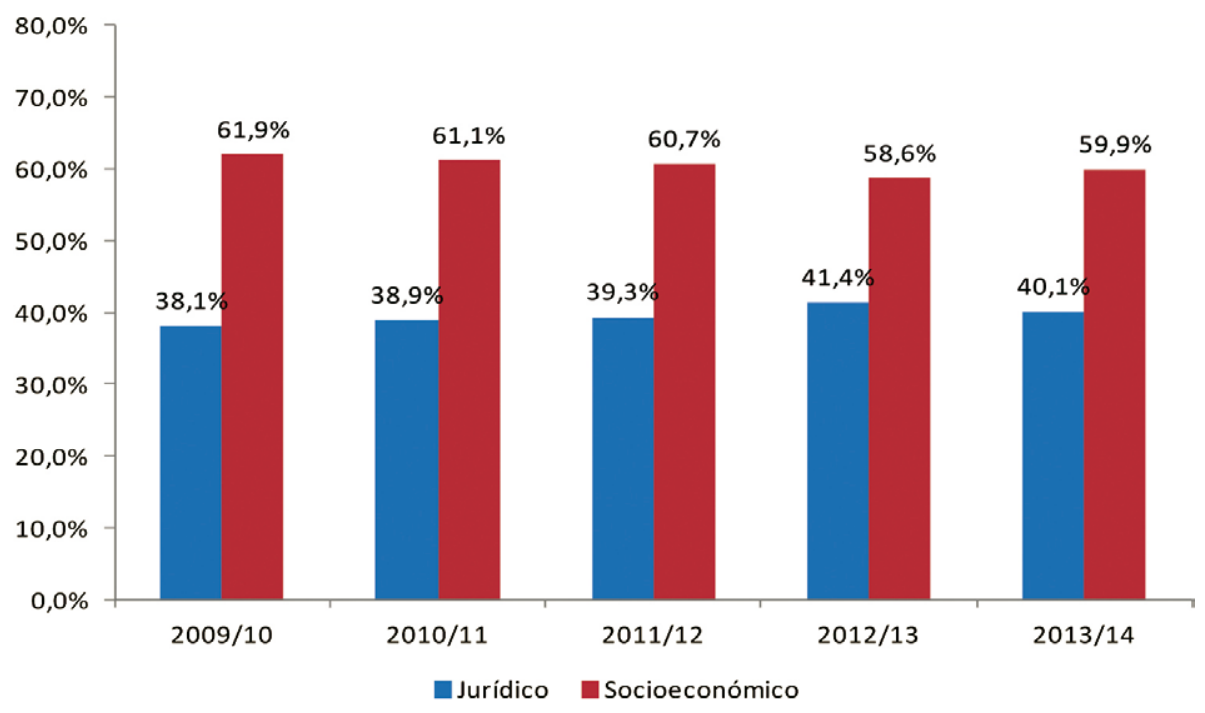

Fuente: Elaboración propia. Datos Secretaría de la Facultad de Ciencias del Trabajo. 
Con la finalidad de analizar más pormenorizadamente la distribución de los trabajos defendidos entre los ańos 2009-14, se ha realizado la tabla 2 en la que se señala el número de trabajos por área de conocimiento del plan de estudios. Junto al dato de trabajos defendidos está el número de trabajos matriculados, lo que nos ha permitido calcular la tasa de rendimiento en el período.

Tabla 2

TFG defendidos por área de conocimiento, 2009-14

\begin{tabular}{|c|c|c|c|c|c|}
\hline \multirow{2}{*}{ Área de conocimiento } & \multicolumn{5}{|c|}{ Curso académico } \\
\hline & $2009 / 10$ & $2010 / 11$ & $2011 / 12$ & $2012 / 13$ & $2013 / 14$ \\
\hline Ciencia Política y de la Administración & & & & 1 & 2 \\
\hline Comercialización e Investigación de Mercados & & & & 2 & 2 \\
\hline Derecho Administrativo & & 3 & 4 & 3 & 7 \\
\hline Derecho Civil & 1 & 1 & 0 & 2 & 3 \\
\hline Derecho del Trabajo y de la Seguridad Social & 4 & 14 & 18 & 47 & 52 \\
\hline Derecho Mercantil & 3 & 3 & 2 & 3 & 5 \\
\hline Economía Aplicada & 3 & 3 & 3 & 11 & 14 \\
\hline Economía Financiera y Contabilidad & & 0 & 0 & 2 & 2 \\
\hline Fundamentos del Análisis Económico & & 3 & 2 & 5 & 6 \\
\hline Hacienda y Economía del Sector Público & & 1 & 0 & 0 & 2 \\
\hline Historia e Instituciones Económicas & 1 & 2 & 1 & 4 & 7 \\
\hline Medicinal Legal y Forense & & & & & 1 \\
\hline Métodos Cuantitativos para la Economía & & 1 & 1 & 0 & 2 \\
\hline Organización de Empresas & 3 & 9 & 13 & 22 & 25 \\
\hline Psicología Social & 3 & 6 & 9 & 13 & 19 \\
\hline Sociología & 3 & 8 & 8 & 19 & 18 \\
\hline TFG defendidos & 21 & 54 & 61 & 133 & 167 \\
\hline TFG matriculados & 31 & 76 & 116 & 185 & 237 \\
\hline Tasa de rendimiento $(\%)$ & 67,7 & 71,1 & 52,6 & 71,9 & 70,5 \\
\hline
\end{tabular}

Fuente: Elaboración propia. Datos Secretaría de la Facultad de Ciencias del Trabajo.

Durante los tres primeros cursos académicos no ofertaban líneas de trabajo las dieciséis áreas del título, sino tan sólo aquellas que participaban en los estudios del itinerario de adaptación. A partir del año 12-13, todas las áreas ofertan y tutorizan trabajos finales. Aún contemplando la particularidad señalada, como se ha visto en el gráfico 2, la distribución entre los dos grandes ámbitos formativos, el jurídico-laboral y el socioeconómico, en todo el período está en torno al $40 / 60 \%$ respectivamente. 
Del conjunto de áreas de nuestro plan de estudios destacan cinco que centralizan la dirección de trabajos: derecho del trabajo y de la seguridad social, organización de empresas, psicología social, sociología y economía aplicada. Estas cinco áreas, en el curso académico pasado, tutorizaron más del $75 \%$ del total de los trabajos y, concretamente, el área de derecho del trabajo se ocupó de más del $30 \%$ del total. Hay que señalar que se aprecia una correlación entre el peso de las áreas en el plan de estudios y el porcentaje total de trabajos que tutorizan los docentes de dichas áreas.

Respecto de la tasa de rendimiento, ésta ha oscilado entre el 52,6\% del curso 2011-12 y el 71,9\% del año 2012-13. Si nos quedamos con estos dos valores solamente, tendríamos una imagen distorsionada de la tasa rendimiento de la asignatura, en tanto que el rendimiento más bajo corresponde a un curso peculiar, en el que se defendieron la mitad de los TFG matriculados. Su excepcionalidad se confirma por los valores del resto de cursos académicos, que oscila entre el 67,7\% del año 2009-10 al 70,5\% del curso 2013-14. La tendencia de esta tasa, visto los dos últimos ańos que corresponden a la primera y segunda promoción del plan de estudios, está por encima del setenta por ciento en los dos casos. Este indicador pone de relieve que aún quedan cuestiones que mejorar, con el fin de acercarnos a las tasas de rendimiento que tan espléndidamente se fijaron para el plan de estudios en el proceso de su verificación. Ciertamente, si no mejoramos la tasa de rendimiento en una asignatura como esta, que es la última que se requiere para poder titular, difícilmente se podrá mejorar la tasa de rendimiento global del plan de estudios.

\section{Resultados de la evaluación de los Trabajos Fin de Grado defendidos}

Entre los años 2009 y 2014 se han evaluado 436 trabajos en la Facultad de Ciencias del Trabajo de la Universidad de Murcia, de los cuales 300 corresponden a los dos últimos años, a las dos primeras promociones completas del título. La experiencia acumulada por el profesorado entre 2009 y 2012 en la evaluación de trabajos, facilitó el que se pudiesen afrontar más adecuadamente las centenares de evaluaciones de estos dos últimos años. El gráfico 3 representa la evolución de la calificación media, anual y por convocatoria, de los trabajos defendidos en los cinco cursos académicos analizados.

Un primer comentario sobre los resultados de la evaluación, es que ha bajado claramente la nota media obtenida en el curso 2009-10 en relación al 2013-14, siguiendo una disminución paulatina. Este hecho puede obedecer a dos razones: una primera, la experiencia del profesorado en el primer año de evaluaciones era escasa y, por tanto, es probable que se evaluase con cierta generosidad; una segunda, al ser un número pequeño de trabajos presentados en 
este primer año, ante la novedad de la nueva tarea de tutorización, los docentes se preocupan muy en exceso en su labor, junto a un alumnado muy motivado. Realmente, las proporciones de cada elemento explicativo las desconocemos: el hecho cierto es que la nota media de los trabajos evaluados el primer año fue más alta que el de los siguientes.

Gráfico 3

Nota media de los TFG por convocatoria, 2009-14

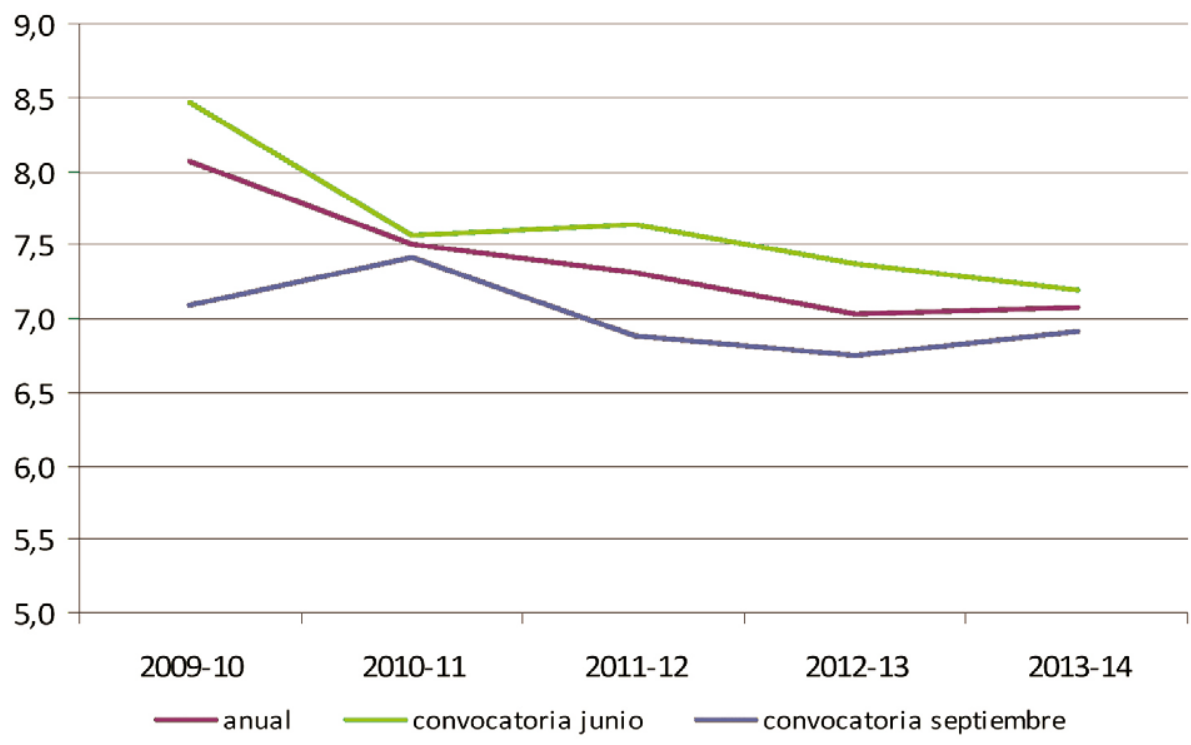

Fuente: Elaboración propia. Datos Secretaría de la Facultad de Ciencias del Trabajo.

Un segundo comentario, en la convocatoria ordinaria de junio se obtiene una mejor calificación media que en la extraordinaria de septiembre, en su momento, hoy correspondiente a la de julio. Resaltada esa diferencia entre convocatoria, el comportamiento de las mismas a lo largo del período es idéntica a la nota media anual.

Estas valoraciones se pueden apreciar mejor con los datos recogidos en la tabla 3. En ella aparece la nota media por convocatoria, la desviación típica y el coeficiente de variación de las calificaciones obtenidas en cada trabajo. Estas medidas explican el grado de dispersión de los datos con respecto al promedio y la homogeneidad de las notas. Respecto de la nota media de los trabajos evaluados en estos cinco cursos, se puede afirmar que los tres primeros, 2009-12, están por encima de 7,30 puntos de calificación media, llegando hasta el 8,47 en la con- 
Tabla 3

Calificaciones TFG por convocatoria, 2009-2014

\begin{tabular}{|c|c|c|c|c|c|}
\hline Curso & Convocatoria & $\begin{array}{c}\mathrm{N} \cdot{ }^{\circ} \\
\text { estudiantes }\end{array}$ & $\begin{array}{l}\text { Nota } \\
\text { media }\end{array}$ & $\begin{array}{c}\text { Desv. } \\
\text { tip. }\end{array}$ & $\begin{array}{l}\text { Coef. } \\
\text { variac. }\end{array}$ \\
\hline \multirow{4}{*}{$2009-10$} & Febrero & - & - & - & - \\
\hline & Junio & 15 & 8,47 & 1,06 & 0,12 \\
\hline & Septiembre & 6 & 7,08 & 1,74 & 0,25 \\
\hline & TOTAL & 21 & 8,07 & 1,43 & 0,18 \\
\hline \multirow{4}{*}{$2010-11$} & Febrero & - & - & - & - \\
\hline & Junio & 35 & 7,56 & 1,49 & 0,20 \\
\hline & Septiembre & 19 & 7,42 & 1,17 & 0,16 \\
\hline & TOTAL & 54 & 7,51 & 1,39 & 0,18 \\
\hline \multirow{4}{*}{$2011-12$} & Febrero & - & - & - & - \\
\hline & Junio & 35 & 7,64 & 1,04 & 0,14 \\
\hline & Septiembre & 26 & 6,88 & 1,67 & 0,24 \\
\hline & TOTAL & 61 & 7,32 & 1,39 & 0,19 \\
\hline \multirow{4}{*}{$2012-13$} & Febrero & 5 & 5,28 & 0,47 & 0,09 \\
\hline & Junio & 72 & 7,37 & 1,37 & 0,19 \\
\hline & Julio & 56 & 6,75 & 1,66 & 0,25 \\
\hline & TOTAL & 133 & 7,03 & 1,55 & 0,22 \\
\hline \multirow{4}{*}{ 2013-14 } & Febrero & 8 & 7,48 & 1,36 & 0,18 \\
\hline & Junio & 78 & 7,20 & 1,38 & 0,19 \\
\hline & Julio & 81 & 6,92 & 1,64 & 0,24 \\
\hline & TOTAL & 167 & 7,08 & 1,52 & 0,21 \\
\hline
\end{tabular}

Fuente: Elaboración propia. Datos Secretaría de la Facultad de Ciencias del Trabajo.

vocatoria de junio de 2010. La desviación típica oscila entre un valor mínimo de 1,06 y un máximo de 1,67 para estos cursos. La dispersión respecto del valor medio correspondiente no es muy alto; el coeficiente de variación se sitúa entre 0,12 y 0,25 , un rango de heterogeneidad no muy elevado.

Los dos últimos cursos de la serie, 2013-14, en los que el número de TFG defendidos fue mayor y por estudiantes de las dos primeras promociones del grado, destaca que la nota media de los trabajos evaluados ha bajado, situándose en torno a los siete puntos de media total y valores que oscilan entre los 7,48 de la convocatoria extraordinaria de febrero de 2014 y el 5,28 de la correspondiente a febrero de 2013. Ciertamente, en estas dos convocatorias se produce la 
mayor oscilación en las calificaciones: las razones de este hecho son variadas y complejas de explicar, donde el tipo de trabajo defendido, tribunal, perfil de los alumnos, pueden ser elementos explicativos. Ahora bien, llama la atención que la desviación típica y el coeficiente de variación, prácticamente, son casi idénticos por convocatorias en ambos cursos, con la salvedad de febrero de 2013.

Para comparar la tendencia de las calificaciones de los TFG en estos dos últimos cursos académicos, se ha realizado una tabla en la que se recoge la calificación media de los egresados de las dos primeras promociones del título de grado. Por un lado, la calificación medía de los titulados de estas promociones oscila entre 6,74 y 6,82 puntos, estando entre un 0,26 y 0,29 puntos por debajo de las calificaciones en los TFG. Por otro lado, los valores de las desviaciones típicas y coeficiente de variación de los egresados mantienen el mismo patrón en estos dos cursos académicos, siendo valores más bajos que los obtenidos en las evaluaciones de los TFG correspondientes. Estos datos resaltan, por tanto, la menor dispersión y mayor homogeneidad de las calificaciones medias de los egresados respecto de las evaluaciones de los trabajos fin de grado.

Tabla 4

Calificación media de los egresados de las promociones 2012-14

\begin{tabular}{c|lcccc}
\hline Curso & Convocatoria & $\begin{array}{c}\text { N. }{ }^{\circ} \\
\text { estudiantes }\end{array}$ & $\begin{array}{c}\text { Nota } \\
\text { media }\end{array}$ & $\begin{array}{c}\text { Desv. } \\
\text { tip. }\end{array}$ & $\begin{array}{c}\text { Coef. } \\
\text { variac. }\end{array}$ \\
\hline \multirow{5}{*}{$2012-13$} & Febrero & 6 & 6,20 & 0,40 & 0,07 \\
& Junio & 71 & 6,86 & 0,68 & 0,10 \\
& Julio & 51 & 6,63 & 0,57 & 0,09 \\
\cline { 2 - 6 } & TOTAL & 128 & 6,74 & 0,65 & 0,10 \\
\hline \multirow{5}{*}{$2013-14$} & Febrero & 8 & 6,32 & 0,40 & 0,06 \\
& Junio & 76 & 7,00 & 0,74 & 0,11 \\
& Julio & 76 & 6,69 & 0,51 & 0,08 \\
\cline { 2 - 6 } & TOTAL & 160 & 6,82 & 0,65 & 0,10 \\
\hline
\end{tabular}

Fuente: Elaboración propia. Datos Secretaría de la Facultad de Ciencias del Trabajo.

El gráfico 4 representa los trabajos finales que, por área de conocimiento, se han matriculado, defendido, junto con la tasa de rendimiento relativa al curso pasado, el 2013-14. Es un ejercicio interesante y muy ilustrativo, sobre el que se pueden plantear diversos comentarios. Muestra la complejidad de las variables que participan a la hora de la realización de un trabajo final, que van desde la preferencia elegida, temática, tutor/a asignado, área de conocimiento a la que pertenece la línea asignada, interés y motivación del alumnado, etc. Hay casos 


\section{Gráfico 4}

TFG matriculados, defendidos y tasa de rendimiento por área de conocimiento,

2013-14

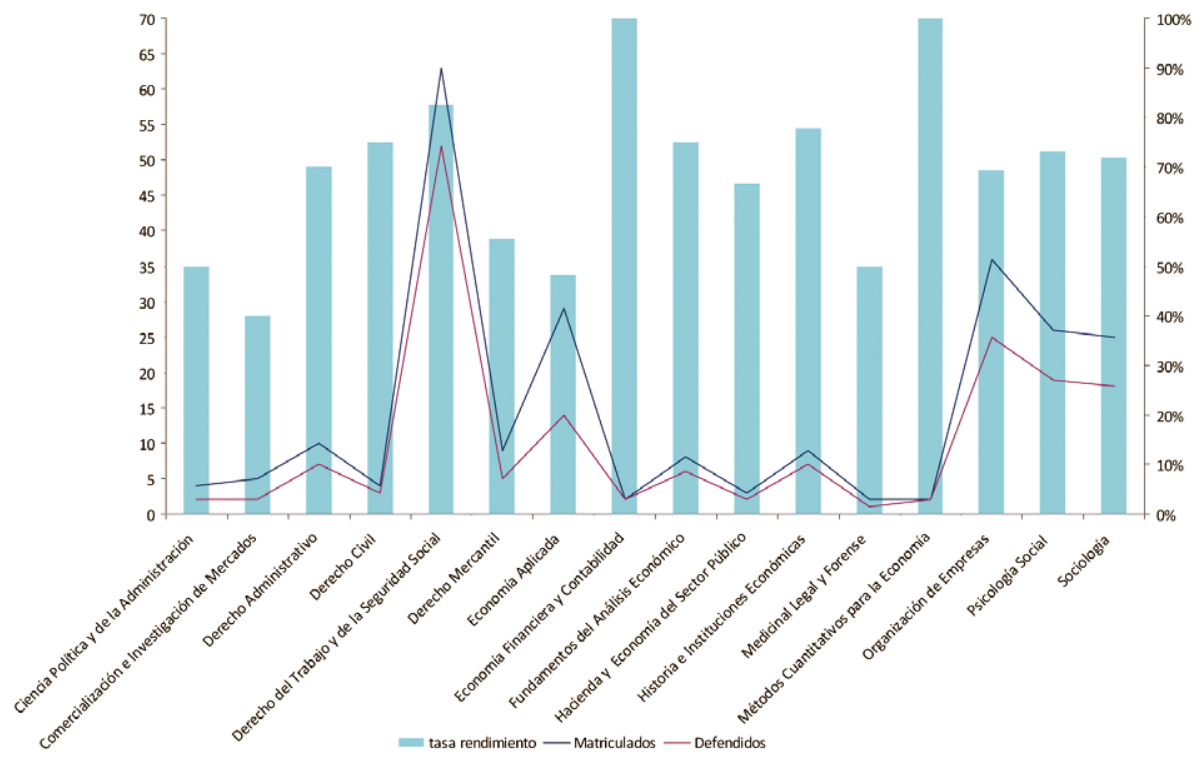

Fuente: Elaboración propia. Datos Secretaría de la Facultad de Ciencias del Trabajo.

con una tasa de rendimiento del $100 \%$ en dos áreas en concreto, economía financiera y contabilidad y métodos cuantitativos para la economía, precisamente dos áreas que no son centrales en el plan de estudios, pero que tienen un éxito pleno. Y otras, al menos cinco áreas (ciencia política, comercialización, mercantil, economía aplicada y medicina legal) que están por debajo de la tasa de rendimiento medio cifrada en el $70 \%$. Las áreas centrales del título alcanzan un rendimiento superior a la media, llegando al $80 \%$. En definitiva, este gráfico expresa con claridad la relación que se produce entre los trabajos matriculados realmente y las expectativas de defensa, que son individuales de cada estudiante, y que finalmente son defendidos.

\section{Medidas adoptadas por la universidad y por la facultad para los cursos 2012-14}

En la Universidad de Murcia (UMU) se presentaron y defendieron Trabajos Fin de Grado por primera vez, de modo general en todas las titulaciones de Grado, en el curso académico 2012/13. Para casi la mayoría de las titulaciones 
este hecho ha sido realmente novedoso para los docentes y los estudiantes. Sólo algunos títulos teníamos una práctica previa acumulada. Por ello, con la experiencia alcanzada en los itinerarios de adaptación a los grados y en los másteres oficiales universitarios sobre TFG y TFM respectivamente, nuestra universidad acometió modificaciones en la normativa relativa a estos aspectos y los centros las adaptaciones pertinentes.

Las medidas promovidas desde el Rectorado de la UMU han sido las siguientes:

- Realización de dos modificaciones sobre el Reglamento por el que se regulan los Trabajos de Fin de Grado y de Fin de Máster en la Universidad de Murcia, aprobado 7 de mayo de 2010 con fechas 27 de julio y 30 de noviembre de 2012.

- Elaboración de un documento donde se dictan instrucciones sobre el procedimiento a seguir para la presentación, defensa y evaluación de los trabajos de fin de grado y de fin de master (aprobado el 24 de septiembre de 2012).

- Publicación de la Guía práctica para la realización de trabajos fin de grado $y$ trabajos fin de master (García Sanz y otros, 2012) elaborada por un grupo de profesores de la UMU y publicada por el servicio de publicaciones de la UMU.

- Creación de una aplicación telemática para gestionar los TFG y TFM, denominada "Gestión TF». Esta plataforma es accesible para los estudiantes desde el Aula Virtual en el sitio de la asignatura TFG y para el gestor y el coordinador del TFG desde la dirección https://tf.um.es.

El desarrollo de esta aplicación ha sido, de forma secuencial, en tres fases. En una primera, la plataforma virtual se utilizó para el proceso de asignación de línea y tutor a los matriculados en la asignatura, atendiendo a sus preferencias. En una segunda, gestionó la entrega y depósito del TFG por parte de los alumnos y la validación por parte de los tutores de los trabajos presentados por sus estudiantes. En la tercera fase, la plataforma informática permite la publicación de los tribunales y los alumnos adscritos a cada uno de ellos. Esta aplicación está resultando muy útil en la gestión de los trabajos finales, a pesar de que se necesitó todo el curso académico 2012-13 para su puesta en marcha.

- Creación de un espacio dentro del Aula Virtual para la comunicación entre el tutor y el alumno, con la finalidad de facilitar el desarrollo y seguimiento del trabajo.

- Promoción de cursos de formación para el profesorado sobre el trabajo fin de grado y fin de máster desde el Centro de Formación y Desarrollo Profesional (CFDP) de la UMU. Este organismo inició en el año 2012 una modalidad de formación denominada "La formación por centros» 
Imagen 1

Ventana de la aplicación informática que gestiona TFG/TFM

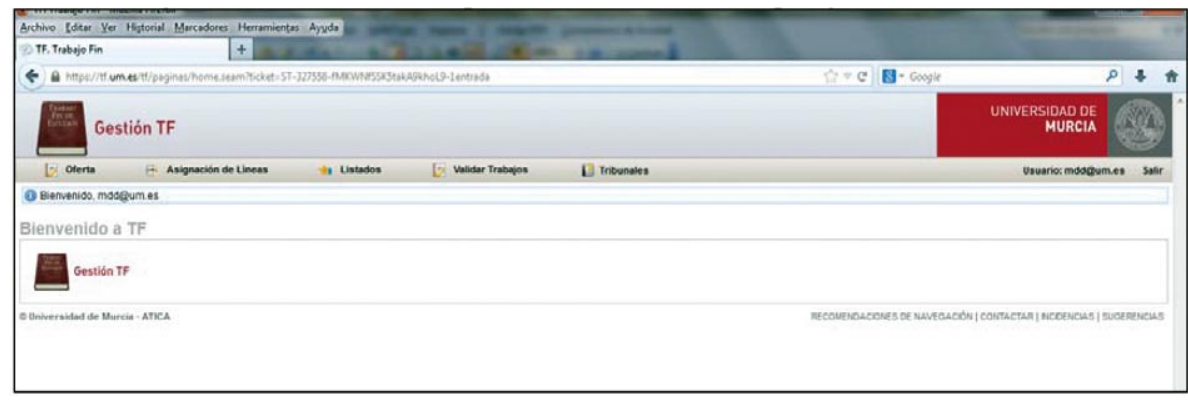

para dar respuesta a las necesidades comunes que tienen las facultades de nuestra universidad. En dicho año, la formación específica se centró sobre al TFG, dirigida a los profesores que tutorizaran trabajos finales. El plan fue diseñado para ser ejecutado en dos etapas. La primera fase se destinó a formar a los profesores designados por los responsables de los Centros. La actividad formativa consistió en nueve sesiones impartidas sobre diferentes aspectos, como presentación, conceptualización y tutorización de los TFG, búsqueda y gestión de la información, exposición y defensa del trabajo y evaluación del mismo. La metodología empleada ha sido semipresencial. La segunda fase fue la acción formativa sobre el TFG, que planificó cada Centro y la impartieron los docentes formados en la primera fase. Estos «formadores» fueron los encargados de atender la formación de los colegas, con el fin de promover acciones de mejora tangibles en cada una de los centros.

Las medidas iniciadas desde la Facultad de Ciencias del Trabajo han sido varias:

- Modificación de la Normativa del trabajo fin de grado de la Facultad de Ciencias del Trabajo, aprobada 28 de octubre de 2010, para adaptarla a las modificaciones introducidas en Reglamento que regula los TFG. La modificación se aprobó el 7 de febrero de 2013.

-Elaboración de un documento denominado "Manual del Alumno" que recoge la información específica para el alumnado matriculado en la asignatura de TFG de nuestro Grado. El documento contiene información detallada sobre la definición, competencias, modalidades de trabajos (anexo 7.1), evaluación (anexo 7.2), el calendario aproximado para llevar a cabo las distintas reuniones de seguimiento y una descripción del contenido de cada sesión (anexo 7.3), orientaciones para la exposición y de- 
fensa (anexo 7.4), etc. El documento pretende ser una guía exhaustiva de todo lo que el alumno debe saber sobre el TFG y ha sido de gran ayuda para los estudiantes que tuvieron que realizar su trabajo final en los últimos cursos académicos.

— De forma complementaria, se ha elaborado el «Manual del Profesor» con información específica para los profesores que tutorizan los TFG.

-Elaboración de las rúbricas de evaluación de la memoria, exposición y defensa del trabajo final de grado. Estos documentos fueron elaborados por un grupo de trabajo dependiente de la Comisión de Grado de la Facultad de Ciencias del Trabajo, que los aprobó en la sesión de 5 de diciembre de 2012. El anexo 7.5 recoge las plantillas con los criterios de calidad y los niveles de logro para la evaluación, exposición y defensa de la memoria del trabajo fin de grado. Estas rúbricas son unos instrumentos de transparencia muy valiosos para los estudiantes, tutores y miembros de los tribunales evaluadores. Además, son un referente clave para los alumnos ya que tienen las evidencias concretas para proceder a su autoevaluación.

— Realización de un curso de formación sobre el TFG dirigido a los docentes del centro, incluida en el plan específico de formación que promueve el centro.

\section{Conclusiones}

Tras cinco años de experiencia en la gestión, tutorización y evaluación del trabajo final de titulación podemos señalar, a modo de reflexiones finales, las siguientes cuestiones:

- La adaptación de las titulaciones del sistema universitario estatal a los requerimientos del plan Bolonia, introdujo en todos los títulos una asignatura nueva, para la gran mayoría de estudios, denominada trabajo fin de grado o trabajo fin de máster según corresponda a estudios de grado o de máster. Esta materia ha supuesto no pocas complicaciones para los gestores, los docentes y los propios estudiantes. Por un lado, por la falta de experiencia de muchos de los títulos en la organización, planificación y gestión de la asignatura y, por otro lado, porque el profesorado no tenía de modo general la formación adecuada para llevar su tarea con éxito.

- La evolución de esta asignatura mediante tribunal, supone la movilización de muchos recursos docentes que con los recortes que está sufriendo nuestro sistema universitario, nos encontramos que gran parte del trabajo se realiza por el voluntarismo del profesorado. Además, cuando se reconocen estas tareas, ya sea de tutoría o de participación en tribunales, se 
hacen de modo tan limitado y con tan escaso valor, que en los centros y entre los docentes se genera un destacado malestar.

- Para minimizar algunos de los efectos comentados, se han adoptado medidas desde la institución y desde los centros. La Universidad de Murcia, desde el curso 2012-13 ha desarrollado diversas actuaciones en el plano de la formación y en la creación de herramientas de gestión. Nuestra facultad ha apostado por la formación y por la creación de recursos para los estudiantes y el profesorado. A nuestro juicio, la elaboración del Manual de alumno y el Manual del profesor que incluyen diversos aspectos, entre ellas, las rúbricas de evaluación de la memoria, de la exposición y defensa del TFG, se han convertido en herramientas imprescindibles para la mejora de la asignatura TFG.

- Finalmente, ponemos algún ejemplo de asuntos aún no resueltos para la discusión. Uno a priori sencillo, el establecimiento de unas normas de estilo para el TFG. Pues no está resultando fácil, ya que en nuestros títulos conviven dos grandes tradiciones, la jurídico-laboral y la económico social, de tal modo que unos argumentan que las citas deben seguir las normas de esta o aquella tradición, otros arguyen otros elementos, sobre una cuestión que debiera ser específica y común a las relaciones laborales.

\section{Bibliografía}

GARCía SANZ y otros (2012). Guía práctica para la realización de trabajos fin de grado y trabajos fin de máster, Murcia, Editum.

Manual del alumno http://www.um.es/documents/15559/2045365/Manual+ Alumno+TFG_.pdf/8b698785-ca42-4007-9753-8b6afbae7a28

Normativa del Trabajo Fin de Grado de la Facultad de Ciencias del Trabajo http:// www.um.es/documents/15559/2045365/normativa.pdf/4373820f-0dca-4a82-b153fe79a5464578

Reglamento por el que se regulan los Trabajos de Fin de Grado y de Fin de Máster en la Universidad de Murcia http://www.um.es/documents/15559/58913/ Normativa+universidad+de+Murcia+TFG.p df/2edcf0ac-0e25-420a-9faa$04 \mathrm{~d} 7 \mathrm{a} 10 \mathrm{~d} 87 \mathrm{e} 1$

Resolución del Rector por la que se dictan instrucciones sobre el procedimiento a seguir para la presentación, defensa y evaluación de los Trabajos de Fin de Grado y de Fin de Máster http://www.um.es/c/document_library/get_file?uuid=4d0adfd1-8cf9-40ce8b29-de3cc6837273\&groupId=10156

Reglamento por el que se regulan los Trabajos de Fin De Grado y de Fin de Máster en la Universidad de Murcia, que entrará en vigor en el curso 2015-16. http://www. um.es/documents/15559/58913/PLAN+Reglamento+TFG-TFM_FIRMADO. pdf/086ec379-e6ee-4d90-a60b-51dbd459395c 


\section{Anexos}

\section{Anexo 7.1. Modalidades de Trabajo Fin de Grado}

Las modalidades de TFG más habituales en el Grado en Relaciones Laborales y Recursos Humanos son las siguientes: trabajo documental, trabajo empírico, estudio de un caso y proyecto de intervención social.

\section{Trabajo documental}

Los trabajos documentales pueden definirse como un conjunto de informaciones precisas en relación a un tema determinado que, para poder comunicar una serie de resultados de forma sistemática y organizada, necesita un proceso de búsqueda e interpretación exhaustiva de las diversas fuentes documentales. Los trabajos documentales pueden ser de dos tipos:

- Panorámico. Es aquel que pretende ofrecer una serie de estudios basados en la síntesis de un conjunto de conceptos y en las exposición de ideas. Por ejemplo, un trabajo documental panorámico sería una puesta al día de las investigaciones realizadas sobre un tema determinado. Es decir, un trabajo que parte de lo que ya está hecho, escrito e investigado y lo que hacen es reflejar el estado de la cuestión.

- Monográfico. Implica una mayor carga de investigación y de análisis, de forma que tratan de generar nuevos conceptos a sumar a las investigaciones ya realizadas.

Las fases del trabajo documental son:

1. Fase inicial. En esta fase se plantea el estado de la cuestión del tema estudiado, mediante un análisis de tendencias científicas, la consulta de autores y estudios recientes y la especificación de la evolución de conceptos, términos y objetos de estudio. Así mismo, en esta fase se reseñan las fuentes consultadas. Por tanto, en esta etapa las tareas a desarrollar son:

— Definir el objetivo de la búsqueda.

- Búsqueda y selección de documentos (palabras clave).

- Recoger la información. Hacer explícitos los criterios de recogida y análisis de la información.

- Determinar las fuentes estadísticas a utilizar, seleccionar las variables y extraer la información.

2. Fase de desarrollo. Es el cuerpo central del TFG. En esta fase se definirá la hipótesis de trabajo, la metodología seguida y, por último, el planteamiento y los resultados del trabajo. En esta etapa, el alumno debe: 
- Sintetizar y reestructurar la información. Algunos criterios pueden ser: fecha publicación, región-país, tipo de estudio, tamaño muestra, etc.

- Presentar la información: adecuación del vocabulario, citas, etc.

- Tratamiento de la información: aplicar los métodos estadísticos y de análisis de datos adecuados.

- Sintetizar la información en cuadros y/o gráficos.

- Análisis de resultados.

3. Fase final. Establecimiento de conclusiones (síntesis del estudio) y propuestas de futuro. En esta etapa, el alumno debe:

- Sintetizar de forma seria y razonada los elementos que se derivan de la investigación y que suponen una aportación a la comunidad científica.

El esquema básico del trabajo documental es:

- Introducción. En este apartado se explica con claridad de qué va el trabajo y qué se desea hacer. Los elementos a tratar son:

- Planteamiento y justificación del problema de investigación.

- Antecedentes y estado actual del tema (Descripción y valoración de los estudios realizados).

- Fuentes documentales (Búsqueda de documentos, seleccionar los documentos, comparar fuentes, análisis del contenido de las fuentes y recogida de información).

- Fuentes estadísticas: búsqueda de fuente, comparación de metodologías y/o definición de variables según distintas fuentes, extracción de los datos.

- Hipótesis de trabajo. Las hipótesis de trabajo han de ir enmarcadas por el contexto en el que se halla, y se compone de una serie de ideas u objetivos fundamentales de carácter general, así como de interrogantes específicos que contribuyen a la evolución y minuciosidad del trabajo de investigación.

- Exposición del contexto sobre el que se investiga.

- Establecimiento del objetivo(s) general(es) y específicos del trabajo.

- Variables: El conjunto de parámetros que van estar presentes en el análisis bibliográfico y en el trabajo de fuentes. Por ejemplo, escasez de fuentes, selección de archivos o fondos de distinta naturaleza, extracción de los datos cuantitativos, etc.

- Metodología de trabajo. Indicar las pautas con las que se ha realizado el trabajo de investigación, incluyendo las técnicas de trabajo utilizadas, métodos específicos empleados y la incorporación de las TIC. 
- Planteamiento y resultados del trabajo.

- Conclusiones: Son la síntesis de los elementos que se derivan de la investigación y que suponen una aportación a la comunidad científica.

- Bibliografía.

\section{Trabajo empírico}

El trabajo empírico es un estudio de investigación, cuyo resultado necesita ser contrastado o verificado mediante la experiencia. Un TFG empírico es un documento escrito que permite difundir y dar a conocer a la comunidad académica, científica y no científica el proceso del estudio efectuado de un modo claro, objetivo y conciso.

Las fases que integran la realización de este tipo de trabajos son:

1. Fase previa. Elegir un tema y revisar la documentación que existente sobre ese tema. Por tanto, en esta etapa las tareas a desarrollar son:

— Definir el objetivo de la búsqueda.

- Búsqueda y selección de documentos (palabras clave).

2. Fase de planificación. La planificación del proyecto es el conjunto de decisiones que van a servir de guía para realizar el trabajo. No es el trabajo en sí, sino el plan sistematizado de lo que será el futuro TFG.

- Marco general en el que se contextualiza la investigación.

- Importancia del estudio por su interés científico y educativo.

— Fundamentación teórica y metodológica.

- Planteamiento del problema de investigación.

— Establecimiento de objetivos e hipótesis.

- Metodología de trabajo.

3. Fase de ejecución. Es la fase en la que el investigador realiza el conjunto de acciones planificadas, a fin de obtener la información necesaria para dar respuesta al problema de investigación, lograr los objetivos y/o contrastar las hipótesis.

4. Fase final. Es cuando se analiza la información recogida en la fase de ejecución con las técnicas de análisis de datos (cualitativas y/o cuantitativas) e instrumentos previstos y se redacta el informe de investigación.

Esquema básico del trabajo empírico:

- Introducción. En este apartado se explica con claridad de qué va el trabajo y qué se desea hacer. La introducción debe concluir con la formulación del problema o problemas de investigación en TFG. Estos pro- 
blemas pueden ser de descripción, asociación y/o intervención. Los elementos a tratar son:

- Planteamiento y justificación del problema de investigación.

- Antecedentes y estado actual del tema (Descripción y valoración de los estudios realizados).

- Marco teórico. Plantea el problema de investigación y lo justifica. Se realiza como fruto de la consulta bibliográfica e integra la información pertinente, relevante, selecciona y ordenada, de tal manera que es posible ubicar el estudio en un contexto teórico-metodológico bien definido y acotado, relacionado con el tema investigado.

- Objetivos y/o hipótesis. Los objetivos constituyen aquello que se pretende conseguir y se expresan como proposiciones orientadas a definir los logros que se esperan obtener como resultados de la investigación. Se deben redactar que comiencen por un infinitivo. Hay que distinguir entre objetivos generales y objetivos específicos.

Las hipótesis son enunciados o proposiciones que constituyen suposiciones o conjeturas probables y que, apoyándose en una serie de conocimientos organizados y sistematizados, pueden presentarse como respuesta a los problemas de investigación. Se pueden redactar mediante el condicional (si,...entonces) o en forma de enunciado matemático.

- Metodología de trabajo (Método, Diseño). Es el procedimiento elegido para poder lograr los objetivos de la investigación y/o contrastar las hipótesis formuladas de acuerdo con unos planteamientos teóricos-metodológicos. Se describe la investigación con tal detalle que pueda ser replicada. Está integrada por:

- Descripción de la población y la muestra.

- Descripción de las variables.

- Descripción de los materiales y/o instrumentos.

- Descripción del método y el procedimiento.

- Cronograma de actuación.

- Recogida de información: instrumentos y procedimiento.

- Plan de análisis de la información.

— Análisis e interpretación de los resultados.

- Conclusiones. Son la síntesis de los aspectos más relevantes de los resultados obtenidos y las discusiones realizadas, siempre en relación con el problema, los objetivos y/o las hipótesis.

- Bibliografía. 


\section{Estudio de un caso}

El objetivo principal de este tipo de trabajos es analizar un tema concreto en un caso particular, por ejemplo, en una empresa.

Las fases que incluye la realización de este tipo de trabajos son:

1. Fase inicial. En esta etapa el alumno debe elegir el tema concreto sobre el que realizará su trabajo y recopilar documentación sobre el mismo. Por tanto, en esta fase las tareas a realizar son:

- Definición del objetivo del TFG.

— Búsqueda y selección de documentos sobre el tema a estudiar.

2. Fase de desarrollo. En esta etapa el alumno debe plantear el marco teórico que sustentará su trabajo. Asimismo, debe escoger y analizar el caso que va a presentar. Por tanto, en esta fase las tareas a realizar son:

- Revisión de los documentos sobre el tema y síntesis de los mismos.

- Elección del caso concreto en el que analizar el tema.

- Diseño de la metodología a seguir para estudiar el caso.

- Exposición de las características generales del caso escogido (contextualización del caso).

- Análisis en profundidad del tema objetivo en el caso elegido.

3. Fase final. En esta etapa el alumno debe extraer conclusiones y recomendaciones para el caso analizado. Por tanto, en esta fase las tareas a realizar son:

— Extracción de las principales conclusiones que se derivan del estudio del caso.

— Planteamiento de recomendaciones de mejora al caso de estudio.

- Redacción del TFG.

El esquema básico del estudio de un caso es:

— Introducción: en este apartado se explica con claridad en qué tema se centra el trabajo, por qué es interesante estudiarlo y en qué caso concreto se va a analizar. Asimismo, se describe cómo se ha estructurado el trabajo.

- Marco teórico: en este punto se presenta la revisión de la literatura realizada. El objetivo de este apartado es definir los conceptos básicos que se utilizan en el trabajo y explicar, desde un punto de vista teórico, los aspectos que se analizarán posteriormente en el caso práctico.

- Metodología del estudio realizado: en este apartado se dejan claros qué aspectos se van a analizar en el caso, qué información se utiliza para ello y cómo se ha recopilado. 
- Descripción general del caso: en este epígrafe se señalan las características básicas del caso. Por ejemplo, si se trata de una empresa: sector de actividad, mercado, tamaño, tipo de propiedad, etc. así como una brevísima descripción de sus hitos históricos.

- Análisis del caso: en esta sección se presenta la información obtenida sobre el caso respecto al tema del TFG.

El alumno debe interpretar esta información teniendo en cuenta la revisión de la literatura realizada.

- Conclusiones y recomendaciones: en este apartado se debe incluir una síntesis de los aspectos más relevantes observados en el caso, así como propuestas de mejora.

- Bibliografía.

\section{Proyecto de intervención social}

El proyecto de intervención social es un trabajo en el que se elabora, de manera fundamentada y sistemática, propuestas de actuación para intervenir profesionalmente sobre necesidades o problemas sociales. Un TFG de intervención social consistirá en el diseño de un proyecto relacionado con las aplicaciones prácticas de la titulación (inserción laboral, desarrollo local, orientación...).

Las fases que integran la realización de este tipo de trabajos son:

1. Fase inicial. Es la fase de identificación de la problemática objeto de la intervención y del marco normativo o teórico del proyecto.

2. Fase de desarrollo. Es la fase de diseño de los diferentes aspectos que constituyen el proyecto de investigación.

El esquema básico del proyecto de intervención social es:

— Introducción. En este apartado se identifica con claridad la denominación del trabajo y se presenta, de manera resumida, el problema o necesidad sobre la que se plantea la intervención, los referentes teóricos o normativos que orientan el proyecto y sus principales elementos.

- Justificación de la intervención. En este punto el alumno deberá describir:

- El territorio y la población objeto de la intervención.

- El problema o situación que se quiere afrontar y los motivos de la selección de ese problema o situación entre los detectados en la zona.

- Se considera necesario que el alumno justifique, de manera teórica, la necesidad de la intervención y los principios que la orientan. 
Resultados de la experiencia en la asignatura Trabajo Fin de Grado

en el título de Relaciones Laborales y Recursos Humanos

- Descripción de la intervención. En este apartado deberán detallarse los elementos básicos del proyecto de intervención:

- Objetivo general y objetivos específicos del proyecto.

- Acciones o actividades a desarrollar, ordenadas jerárquicamente.

- Resultados que previsiblemente obtendrán estas actividades. En caso necesario, habrá que detallar cuáles son las condiciones que deben cumplirse para que la intervención tenga éxito y los factores de riesgo que se detecten, previendo mecanismos para evitarlos.

- Cronograma.

- Recursos necesarios y costes de la intervención, relacionados con las actividades a desarrollar.

- Mecanismos de seguimiento y criterios o indicadores de evaluación.

- Conclusiones.

- Bibliografía.

\section{Anexo 7.2. Evaluación del Trabajo Fin de Grado}

\section{Evaluación por competencias}

La evaluación del TFG consta de tres instrumentos: la memoria escrita, la exposición pública y la defensa del trabajo. La siguiente tabla indica el peso de cada uno de ellos, las plantillas que se utilizan para evaluarlos y el responsable de su evaluación:

\begin{tabular}{lccc}
\hline \multicolumn{1}{c}{ Instrumento } & Peso & Plantillas & Evaluador \\
\hline Memoria escrita & $70 \%$ & 1 & Tribunal \\
Exposición del trabajo & $20 \%$ & 2 & Tribunal \\
Defensa del trabajo & $10 \%$ & 3 & Tribunal \\
\hline
\end{tabular}

\section{Sesión de exposición pública}

Desde la coordinación de Grado se establecerán los mecanismos necesarios para llevar a cabo la sesión de evaluación por parte de los tribunales, utilizando los espacios de la Facultad de Ciencias del Trabajo. Los tribunales y el orden de intervención serán publicados a partir del último día de depósito del TFG, una vez que se tenga conocimiento de los trabajos que se presentan.

Para que un trabajo pueda ser defendido deberá contar con la validación o autorización del tutor, así como con el informe correspondiente según establece el artículo 4.g de la Resolución del Rector por la que se dictan instrucciones sobre el procedimiento a seguir para la presentación, defensa y evaluación de los trabajos de fin de grado y de fin de máster, de fecha 24 de septiembre de 2012. 
El proceso de evaluación del TFG por parte de los tribunales estará basado en plantillas de evidencias (o rúbricas) que determinan si el alumno ha demostrado un determinado resultado de aprendizaje y en qué grado. De esta forma, la actuación del tutor y de los evaluadores se guiará siempre por las plantillas, favoreciendo así una mayor objetividad y que todos los alumnos tengan un mismo procedimiento de evaluación de su trabajo.

Las plantillas de evidencias serán públicas tanto para los alumnos matriculados en la asignatura como para los tutores, y no podrán modificarse.

\section{Anexo 7.3. Guía para el desarrollo del Trabajo Fin de Grado}

A continuación se detalla, de forma orientativa, el número de sesiones de supervisión entre el tutor y el alumno y las cuestiones a tratar en el desarrollo de las mismas. De esta forma se intenta que haya una homogeneidad en el trabajo del alumno y en la evaluación de los distintos TFG.

\section{Sesión 1. Presentación de la asignatura}

La coordinación de Grado se ocupará de esta presentación. Será una sesión de 45 minutos para todos los alumnos matriculados, en la que se explica el funcionamiento de la asignatura, la normativa que rige el TFG (http://www. um.es/web/cctrabajo/contenido/normativa\#tfg) y las fechas de depósito y defensa del mismo, en las convocatorias ordinaria de mayo-junio y extraordinaria de julio.

Tras la sesión de presentación de la asignatura el alumno se pondrá en contacto con su tutor para establecer la fecha de la primera reunión de supervisión.

Sesión 2. Primera reunión de supervisión con el tutor (28 de enero al 14 de febrero)

\begin{tabular}{|l|l|}
\hline Trabajo previo & Ninguno \\
\hline Objetivo & Establecimiento de objetivos \\
\hline Duración & 45 minutos \\
\hline $\begin{array}{l}\text { Puntos que deben tratarse } \\
\text { con el alumno }\end{array}$ & $\begin{array}{l}\text { 1. Determinar el objetivo general del TFG dentro de la } \\
\text { línea propuesta. } \\
\text { 3. Orientar para realizar una búsqueda bibliográfica y } \\
\text { entregar lecturas iniciales. }\end{array}$ \\
\hline
\end{tabular}


Sesión 3. Segunda reunión de supervisión con el tutor (17 de febrero al 11 de abril)

\begin{tabular}{|c|c|}
\hline Trabajo previo & $\begin{array}{l}\text { El alumno preparará un documento que incluirá: } \\
\text { 1. Un esquema, guión o índice del tema del TFG. } \\
\text { 2. Plan de actuación previsto para la consecución del } \\
\text { objetivo. } \\
\text { 3. Revisión bibliográfica realizada. } \\
\text { 4. Este documento deberá enviarlo al tutor, como plazo } \\
\text { límite, dos días hábiles antes de la fecha acordada } \\
\text { para esta reunión. }\end{array}$ \\
\hline Objetivo & Inicio del trabajo. \\
\hline Duración & 45 minutos. \\
\hline $\begin{array}{l}\text { Puntos que deben tratarse } \\
\text { con el alumno }\end{array}$ & $\begin{array}{l}\text { 1. Revisar el documento de trabajo enviado por el } \\
\text { alumno previamente y en la fecha límite acordada. } \\
\text { 2. Revisar el cronograma de trabajo. } \\
\text { 3. Orientar al alumno para el desarrollo del trabajo. }\end{array}$ \\
\hline
\end{tabular}

Sesión 4. Tercera reunión de supervisión con el tutor (28 de abril al 16 de mayo)

\begin{tabular}{|c|c|}
\hline Trabajo previo & $\begin{array}{l}\text { En fecha acordada, el alumno enviará al tutor un do- } \\
\text { cumento de trabajo que incluya el estado actual del } \\
\text { TFG. } \\
\text { El plazo límite para su entrega será de dos días hábiles } \\
\text { antes de la fecha establecida para esta reunión. }\end{array}$ \\
\hline Objetivo & Revisión del desarrollo del trabajo. \\
\hline Duración & 45 minutos. \\
\hline $\begin{array}{l}\text { Puntos que deben tratarse } \\
\text { con el alumno }\end{array}$ & $\begin{array}{l}\text { 1. Revisar el documento enviado por el alumno. } \\
\text { 2. Orientar al alumno para la finalización del trabajo, } \\
\text { haciendo hincapié en la importancia de especificar } \\
\text { las conclusiones alcanzadas en su trabajo. } \\
\text { 3. Fijar una fecha para el envío de la versión defi- } \\
\text { nitiva del trabajo para la última revisión del tutor } \\
\text { previa al depósito. Fecha tope: } \\
\text { - Convocatoria mayo-junio: } 10 \text { de junio. } \\
\text { - Convocatoria julio: } 3 \text { de septiembre. }\end{array}$ \\
\hline
\end{tabular}




\section{Sesión 5. Revisión de la presentación de la exposición pública del trabajo}

Esta última sesión tiene carácter opcional y dependerá de cada tutor. Esta sesión tendrá como objetivo la revisión de la presentación preparada por el alumno para defender su trabajo mediante exposición pública delante de un tribunal. La fecha y duración (aproximadamente 45 minutos) será acordada por el profesor y el alumno después del depósito del TFG y antes de la defensa (del 24 al 28 de junio o del 9 al 13 de septiembre).

\section{Anexo 7.4. Orientaciones para la elaboración de la exposición y defensa del Trabajo Fin de Grado}

Según especifica la normativa que rige el TFG en esta facultad, la exposición y defensa del TFG debe hacerse apoyándose en un formato de presentación tipo PowerPoint o cualquier otra herramienta similar (impress, prezi, etc.). Esta modalidad implica que tanto la componente visual como la oral son necesarias y complementarias, es decir la componente visual no tendrá sentido si no hay una comunicación oral que la explique.

En la elaboración de este tipo de presentaciones, en primer lugar hay que tener en cuenta a quién va dirigida (audiencia), el lugar donde se va a realizar la exposición y el contenido. Debe contar una historia, combinar texto e imágenes, sin abusar de ellas, introduciéndolas sólo cuando aporten algo y siempre imágenes de calidad y libres (se pueden encontrar en plataformas como Google imágenes o flickr, utilizando la herramienta de filtro avanzado). En la presentación es conveniente huir de los ruidos, es decir, elimina todo aquello que no sea necesario y que pueda provocar que la audiencia se distraiga.

Los pasos a seguir en la elaboración de una presentación visual son:

- Preparación. Este primer paso es muy importante. Hay que reflexionar sobre el contenido que se va a poner en la presentación, cómo lo vamos a organizar, qué efecto perseguimos, a quién va dirigido, y sobre todo, debemos intentar formular ideas de manera que la presentación visual sea una exposición de las principales ideas y/o logros del trabajo. Ten presente que una presentación visual debe comenzar con algo motivador que capte la atención de la audiencia, como puede ser una buena ilustración.

-Diseño. Hay que ofrecer un diseño simple, que no simplista. Debe comunicar de forma eficaz las ideas principales analizadas en el trabajo, los logros, señalar las cuestiones que consideras pendientes, etc. De ser un apoyo a la exposición oral, que ayude a mantener el interés de la audiencia y donde se demuestre que se domina el contenido del trabajo. Es importante que siga una línea cronológica con una introducción, un nudo 
y el desenlace. Algunas recomendaciones útiles a tener en cuenta en el diseño de una presentación visual pueden ser:

- Una idea por pantalla, a lo sumo dos, aunque podemos utilizar varias pantallas para desarrollar una misma idea.

- Organizar la estructura de las pantallas teniendo en cuenta el sentido habitual del barrido ocular. En nuestro contexto cultural el ojo humano tiende a «leer» de izquierda a derecha y de arriba abajo.

- Utilizar grafismos estructurantes y/o señalécticos para combinar texto e imagen en una misma pantalla.

Los grafismos estructurantes son aquellos que nos ayudan a organizar la información, como son cuadros de texto, figuras, llamadas de atención, etc. y los grafismos seńalécticos son los que se utilizan para resaltar, como el color.

- Hacer un buen uso del color. El color no debe de limitarse sólo al fondo de los objetos, también se puede utilizar para resaltar ideas y hacer llamadas de atención. En este tipo de presentaciones la negrita o el subrayado no son adecuados porque son estilos propios de los documentos basados en texto.

- Hay que procurar conseguir un buen contraste entre los diferentes elementos: fondo, texto, ilustraciones, grafismos estructurales... Debe existir unidad en el color, formato y estilo del texto utilizado, ya que ellos favorecerán la percepción y discriminación de los elementos representados.

- La elección del color de fondo tendrá que ver con la iluminación de la sala. En salas iluminadas (luz natural o artificial) es preferible utilizar fondos con colores claros, preferentemente color blanco, gris y colores pastel. Los fondos de colores intensos y oscuros serán utilizados en salas con una iluminación tenue o escasa. Ante la duda, los colores claros suelen visualizarse bien en cualquier sala.

- Es conveniente no exceder de 12 líneas por pantalla, aunque si es posible, no utilizar más de 8 líneas.

- La letra ha de ser clara, grande y legible. Algunos tipos de letra adecuados serían Arial, Tahoma o Verdana. En este tipo de presentaciones no resulta adecuado usar tipos de letra como Times New Roman y Comic Sans.

- En cuanto al tamaño del texto, para facilitar su lectura en la sala, es recomendable en los títulos utilizar un tamaño de fuente entre 2436 puntos, mientras que en el texto utilizaríamos entre 18 y 24.

- Hay que utilizar términos claros y concisos, expuestos preferentemente de forma esquemática para evitar que la exposición se convierta en una copia textual de la memoria del trabajo. 
- Utilizar la imagen en combinación con el texto, multiplicando así el poder de comunicación de ambos.

- Hacer hincapié en las conclusiones del trabajo, ya que constituyen una de las partes más importantes del TFG, por tanto debemos hacer un esfuerzo porque la información sea clara y esté bien organizada.

- Si las conclusiones obtenidas son amplias y referidas a distintas dimensiones, se recomienda realizar un diseño clásico basado en un listado organizado mediante vińetas, pudiendo diferenciar las distintas dimensiones a las que se refiere con filetes, figuras o color.

- EXPOSICIÓN. Debes comenzar atrayendo a la audiencia, hablar con pasión, convencido de lo que estás exponiendo, poner ejemplos y centrarte en desarrollar cuatro ideas básicas.

\section{Anexo 7.5. Plantillas de rúbricas para la evaluación, exposición y defensa de la memoria del Trabajo Fin de Grado}

El proceso de evaluación del TFG estará basado en distintas plantillas de evidencias o rúbricas que determinan si el alumno ha demostrado un determinado resultado de aprendizaje y en qué grado. De esta forma, la actuación del tutor y de los evaluadores se guiará siempre por las plantillas, favoreciendo así una mayor objetividad y que todos los alumnos tengan una misma evaluación de su trabajo. 
Resultados de la experiencia en la asignatura Trabajo Fin de Grado

en el título de Relaciones Laborales y Recursos Humanos

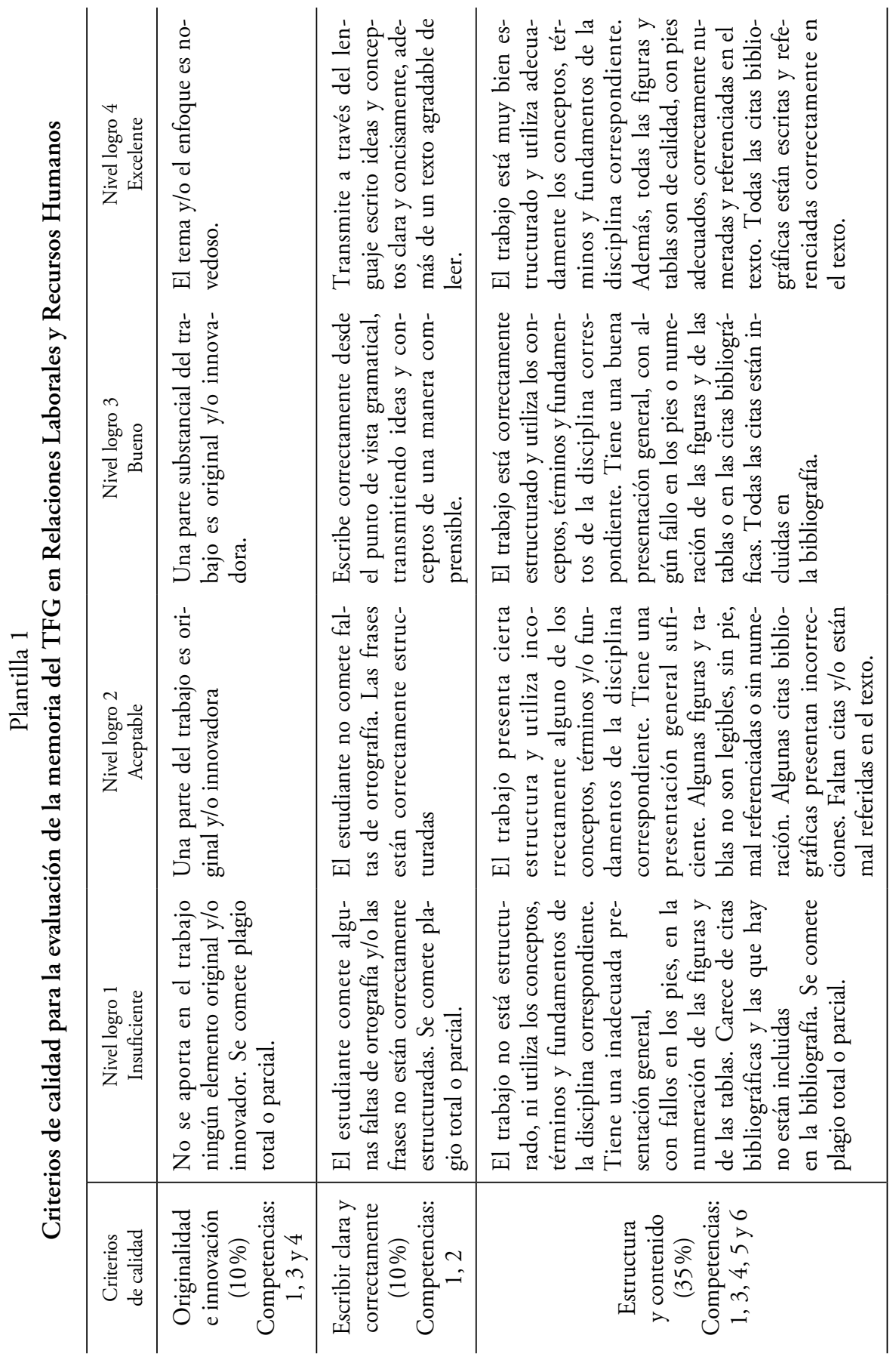




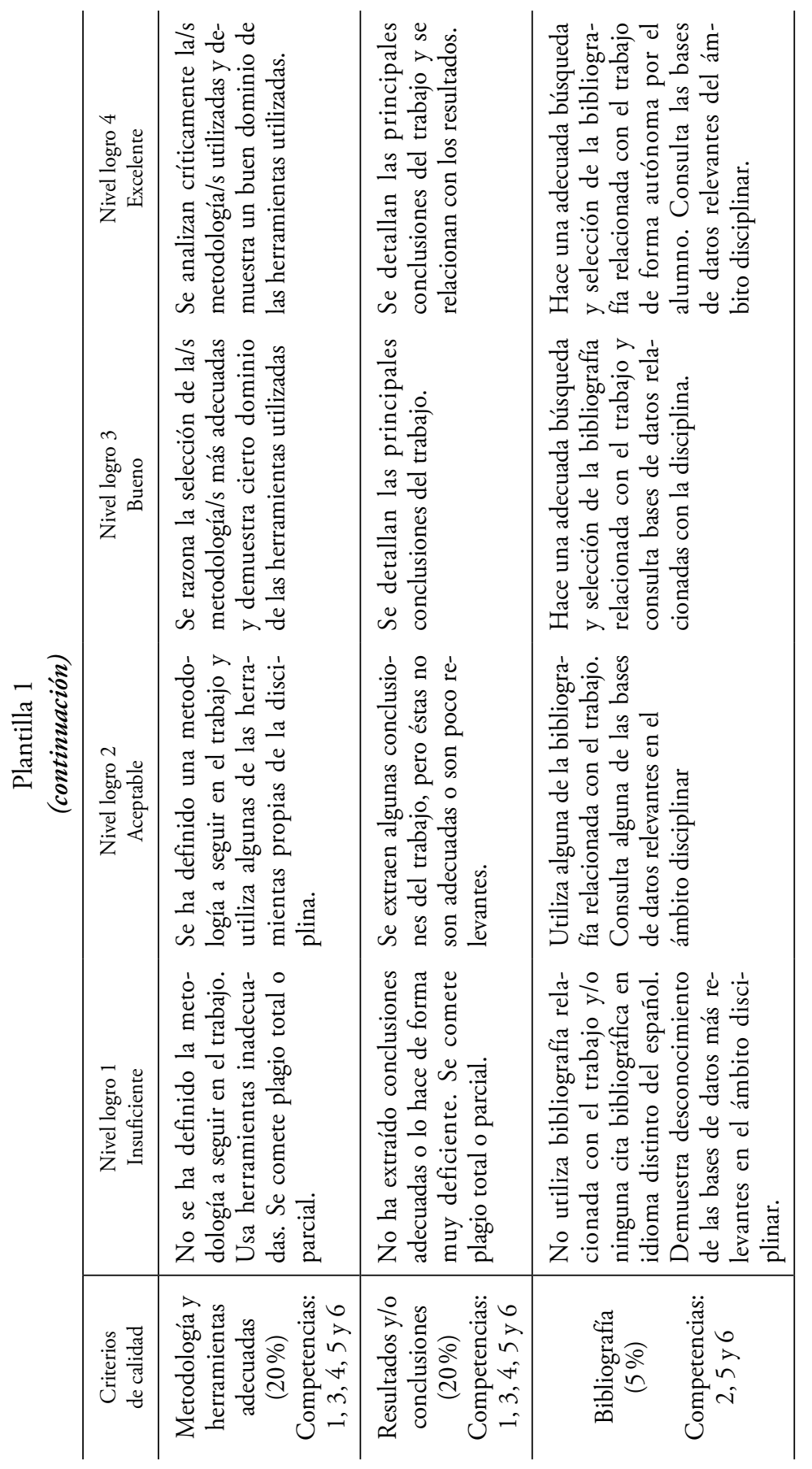


Resultados de la experiencia en la asignatura Trabajo Fin de Grado

en el título de Relaciones Laborales y Recursos Humanos

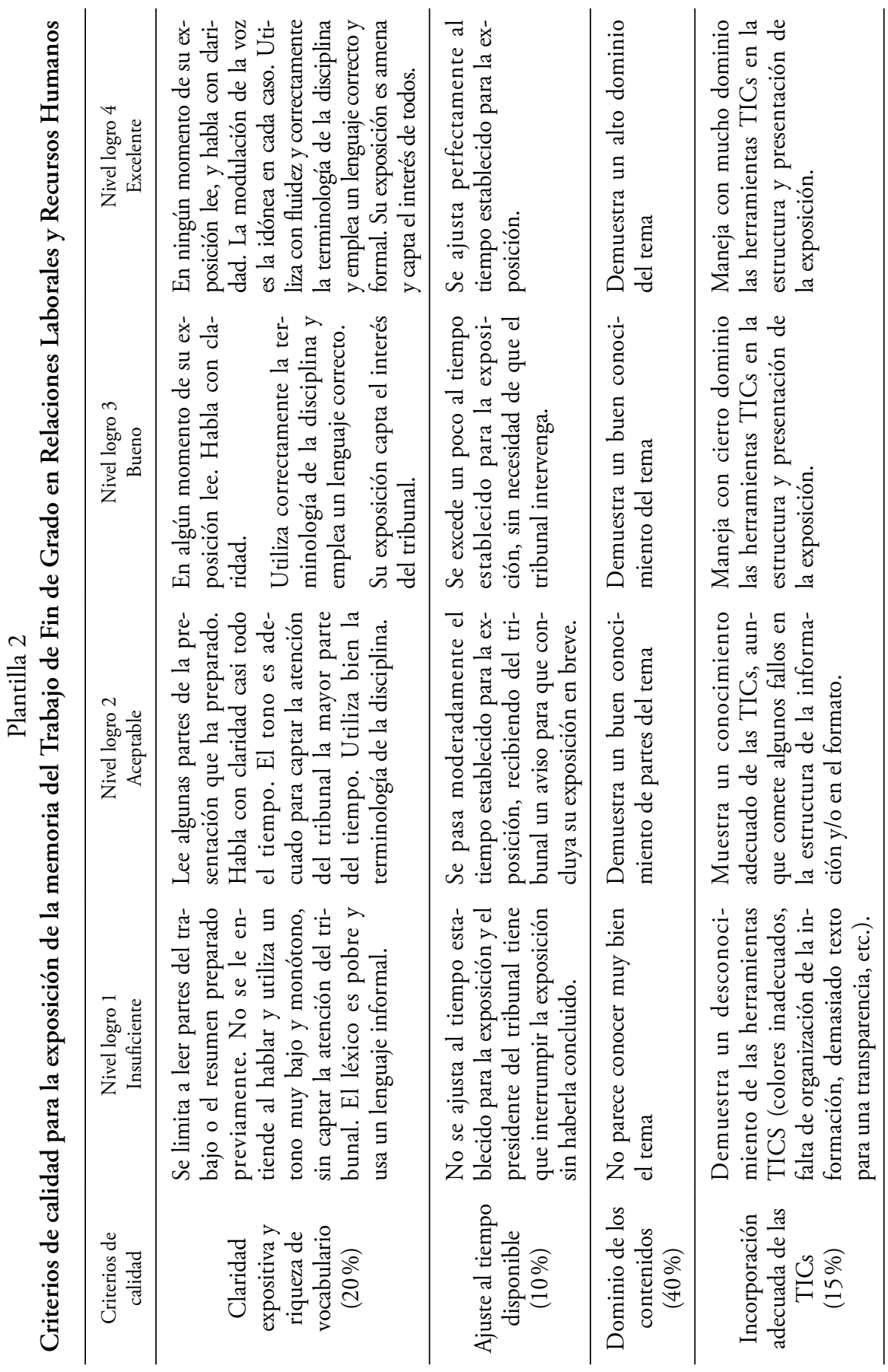



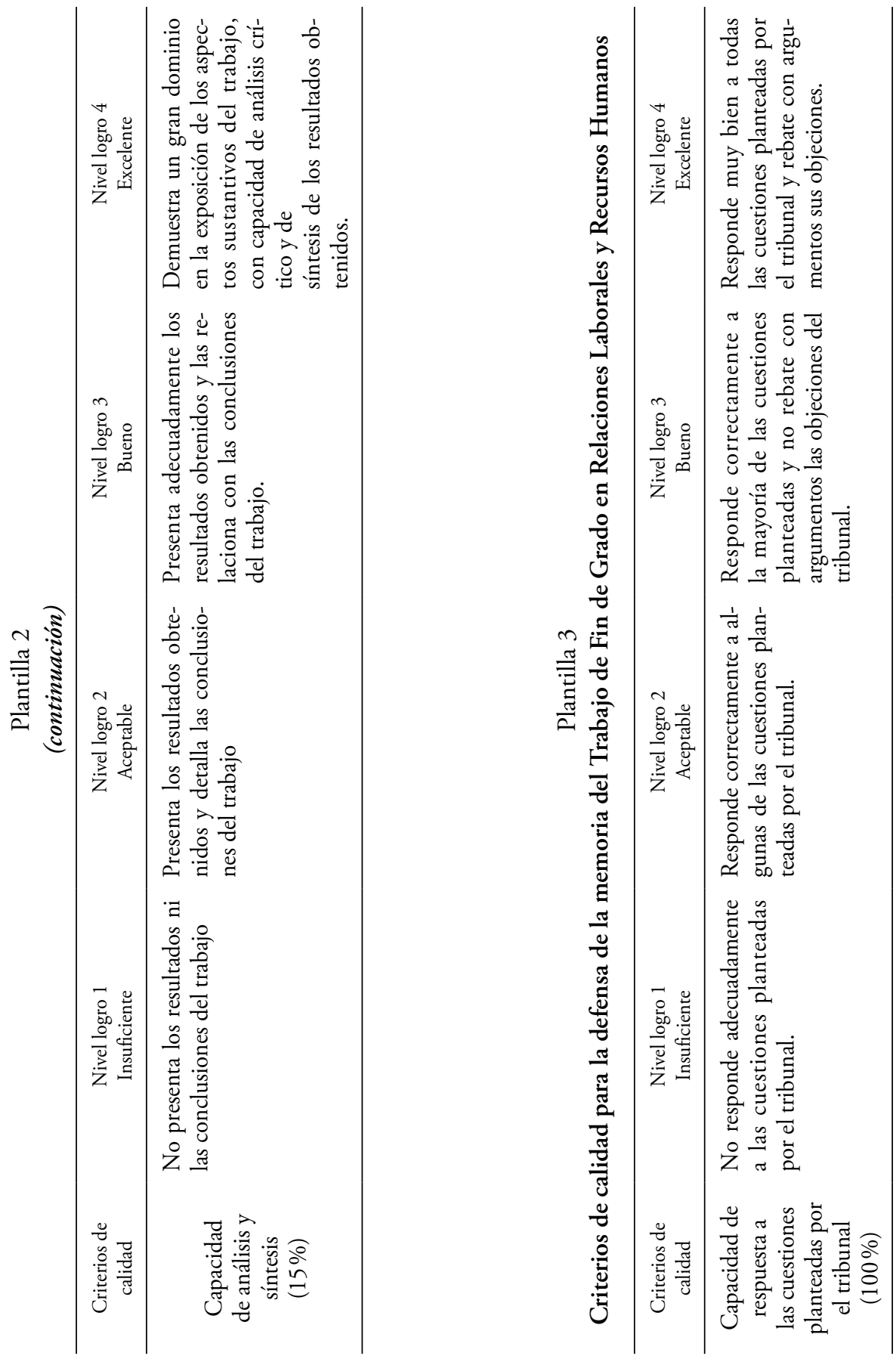